\title{
Determination of the serum antibody level of different age groups of broiler chicken against Infectious Bursal Disease (IBD)
}

\author{
Hossain $\mathrm{MI}^{1}$, Nath $\mathrm{BK}^{2 *}$, Prodhan $\mathrm{MAM}^{3}$ \\ ${ }^{1}$ Dhaka Zoo, Mirpur 1 no., Dkaka. ${ }^{2}$ Department of Dairy and Poultry Science, ${ }^{3}$ Department of Medicine and \\ Surgery, Faculty of Veterinary Medicine, Chittagong Veterinary and Animal Sciences University, Chittagong, \\ Bangladesh.
}

[Received: November 11, Accepted: December 2, 2014]

\begin{abstract}
A study on Infectious Bursal Disease (IBD) was conducted on broiler chicks $(\mathrm{N}=200+70)$ of strains: Cobb-500 and Hubbard classic at Laxmipur district of Bangladesh. The blood sample were collected at day old chicks ( $1^{\text {st }}$ day), pre-vaccinated flocks $\left(11^{\text {th }}\right.$ day) and postvaccinated flocks ( $26^{\text {th }}$ day), to measure the antibody titer by indirect ELISA method. Maternal derived antibody (MDA) mean titer of day old chicks $(\mathrm{N}=40)$ were found $9621.65 \pm 780.78$ and $4232.60 \pm 301.66$ for Cobb-500 and Hubbard classic respectively. MDA mean titer was measured at day eleven chicken $(\mathrm{N}=60)$ before vaccination and found $1963.00 \pm 143$ and $984.16 \pm 126.4037$ respectively. Of these two titers; Cobb-500 strain was found to be protective $(>1000)$ where Hubbard classic was below protective $(<1000)$ titer level. The two flocks of Cobb-500 and Hubbard classic strains of broiler chickens were vaccinated with intermediate (Bursine-2) and intermediate plus (IBD Blen) vaccine respectively at day twelve and serum was harvested on day twenty six. The mean serum titers were found $131.30 \pm 36.04$ and $7413.54 \pm 569.39$ in Cobb-500 and Hubbard classic respectively, where mean titer level of Cobb-500 was below the minimum protective level but Hubbard classic strain was developed 7413.54, protective level. These results were indicating that the maternal derived antibody titer persists above 1000 level hindering the development of antibody titer in vaccinated flocks. However, persistence of MDA titer above 1000 may causes of vaccination failure of IBD vaccine.

Key words: Enzyme Linked Immune Sorbent Assay, Maternally Derived antibody, Infectious Bursal Disease Virus, Vaccine.
\end{abstract}

\section{INTRODUCTION}

Infectious Bursal Disease (IBD) is an important viral disease of poultry throughout the world ${ }^{[1]}$. IBD is an acute, highly contagious viral disease of young chicken and it affects the poultry industries worldwide ${ }^{[2]}$. This disease in poultry which causes heavy economic losses due to immunosuppression in case of subclinical cases ${ }^{[3]}$ and in acute, it is associated with mortalities, hemorrhages with bursa damage ${ }^{[4]}$. The acute form of clinical signs are characterized by sudden unusual calmness in a jubilant flock, vent picking, body tremor, paralysis of both legs, stretched backward with yellowish watery diarrhea, depression, anorexia, prostration and finally death $^{[5]}$. Chicken have a short incubation period and acute cases characterized by high morbidity and variable mortality.

Poultry sector has a tremendous employment generating opportunity by reducing unemployment problem in Bangladesh and other country of world. Poultry meat now accounts for more than $30 \%$ of all meat consumed in Bangladesh. The world's average annual per capita poultry meat consumption is currently $9.5 \mathrm{~kg}{ }^{[6]}$. On the other hand, the growth of this profitable sector is interrupted by a number of infectious and contagious diseases like Newcastle disease, Gumboro disease, Infectious bronchitis, Collibacillosis, Salmonellosis, Fowl cholera, avian influenza and Mycoplasmosis. Moreover, IBD is one of the important diseases, cause heavy economic loss among them. The poultry industry is now in a great challenge to IBD as it appears as emerging and fatal disease throughout the world as like as Bangladesh. Hemorrhage is found in breast and thigh muscles but not always present. Also abnormally swollen liver and kidney, especially kidney full of urinates, most prominently swollen edematous bursa of fabricus from mild to profuse hemorrhage is found in IBD during postmortem examination ${ }^{[7]}$ described the signs of IBD as well as pathological changes occurring in lymphoid organs and observed that peak mortality occurred at four to six days after onset of the disease. IBD in subclinical form was associated with a variant IBDV which varied in ability to cause mortality but invariably caused immunosuppression ${ }^{[8]}$. The most recent survey of international poultry specialists, conducted by World Poultry, highlighted continuing concern in the sector over the sanitary status of poultry. IBD topped the list of the most serious poultry diseases ${ }^{[9]}$. Therefore, the present study was carried out to determine maternally derived antibody titer level on 11 and 26 days of pre and post vaccination chicken against IBD, respectively and to recommend vaccination time of different broiler strain against IBD in Bangladesh prospective.

\section{MATERIALS AND METHODS}

\section{Study area}

The study was done on Infectious Bursal Disease (IBD) in private poultry farm of Laxmipur district of Chittagong division, Bangladesh from a period of July 05, 2012 to December 31, 2012. Day old chicks 
of Cobb-500 and Hubbard classic strain, the progeny of parent stock of Provita and Aftab hatcheries ltd. with a history of vaccinated with oil adjuvant vaccine of IBDV were used. A questionnaire survey was made to estimate the population, strains, diseases, mortality, flock size, vaccination etc. to select the broiler flock for this study. Two medium size broiler farms were selected rearing Cobb-500 and Hubbard classic with a range of population from 500-700 day old chicks.

\section{Sample collection and laboratory study protocal}

Blood sample of day old chicks $(\mathrm{N}=40)$ from two farms of both strain collected by sacrificing the chicks and kept the blood in test tube without using any anticoagulant. The blood was kept in refrigerator for 6 hours and then centrifuged at $738 \mathrm{~g} \mathrm{RCF}$ for 5 minutes. Serum was harvested by pasture pipette into Epindrop tube and preserved at $-20^{\circ} \mathrm{c}$ until further used. As per study design, blood sample $(\mathrm{N}=160)$ were collected from 11 and 26 days old chickens of both strains of Cobb-500 and Hubbard classic from wing vein by $3 \mathrm{ml}$ sterile plastic disposable syringe and kept in test tube as per procedure described before. The serum samples were leveled and preserved in $-20^{\circ} \mathrm{c}$ for further use. Methods for preparation of reagents and application of the assay were described by Marquardt et al. (1980). Antibody was measured by indirect ELISA test as described by IBD ELISA Kit manufacturer, Biochek, Holland. ELISA at a single dilution of serum (1:500) was applied for the detection MDA of IBDV specific antibody. The IBD ELISA kit measured the amount of antibody to IBD in the serum of chickens. Microtiter plates were pre-coated with inactivated IBD antigen. Chicken serum samples diluted and added to the micro titer wells where any anti-IBD antibodies present that bind and form an antigenantibody complex. Non-specific antibodies and other serum proteins were then washed away. Anti-chicken IgG labelled with the enzyme alkaline phosphatase was then added to the wells and binds to any chicken anti-IBD antibodies originally bound to the antigen. After another wash to remove unreacted conjugate, substrate was added in the form of pNPP chromogen. A yellow color was developed if anti-IBD antibody was present and the intensity was directly related to the amount of anti-IBD present in the sample.

\section{I-ELISA test procedure}

$5 \mu \mathrm{l}$ of serum was pipetted directly in a well of a dilution plate (polystyrene microtitre plate). $245 \mu 1$ of Biochek Green sample diluents was added into each well of dilution plate. That gave a 1:50 dilution of serum to diluents in the dilution plate. Coated plate was Removed from sealed bag and recorded location of samples on template. $100 \mu 1$ of Negative control was added into wells A1 and B2. $100 \mu 1$ of positive control was added into wells $\mathrm{C} 1$ and D1. $90 \mu 1$ of sample diluents (Green) was pipetted into each well of a Biochek test plate (not for negative and positive). Diluents that were specific to the kit were added at this point. For instance, $90 \mu \mathrm{l}$ of green diluents were used.
1:50 Serum dilution was mixed with pipette by drawing solution into the pipette and releasing it back into the well. This task was repeated 4 (four) times. Then $10 \mu \mathrm{l}$ sample was taken from the dilution plate containing the 1:50 diluted serum and added it to each corresponding well of the Biochek test kit plate. This gave a final $100 \mu \mathrm{l} /$ well of 1:500 serum dilutions on the Biochek test plate. The plate was covered with lid and incubated at room temperature $\left(22-27^{\circ} \mathrm{c}\right)$ for 30 minutes. Aspirated contents of wells and washed 4 times with wash buffer $(350 \mu$ per well). Inverted plate and tap firmly on absorbent paper. $100 \mu \mathrm{l}$ of conjugate was added into the appropriate wells. The plate was covered with lid and incubated at room temperature $\left(22-27^{\circ} \mathrm{c}\right)$ for 30 minutes. Aspirated contents of wells and washed 4 times with wash buffer $(350 \mu \mathrm{l}$ per well). The plate was inverted and tapped firmly on absorbent paper. $100 \mu 1$ of Substrate was added into the appropriate wells. The plate was with lid and incubated at room temperature $\left(22-27^{\circ} \mathrm{c}\right)$ for 15 minutes. $100 \mu \mathrm{l}$ of stop solution was added into the appropriate wells to stop reaction. Blank the reader on air and recorded the absorbance of controls and samples by reading at 405 nm.

\section{Measurement of titer level}

Measurement of MDA of IBDV in day old chicks $(\mathrm{N}=40)$ : The MDA of both strain of broiler was measured at the age of day-1 by ELISA and recorded. Pre vaccination MDA of IBDV on $11^{\text {th }}$ day $(\mathrm{N}=60)$ : The titer level of both strain of broiler was measured at the age of day-11 by ELISA and recorded. Post vaccination titer level of IBDV on $26^{\text {th }}$ day $(\mathrm{N}=100)$ : The titer level of both strain of broiler was measured at the age of day-26 and also by ELISA and recorded. The IBD positive control was carefully standardized to represent significant amount of antibody to IBD in chicken serum .The relative amount of antibodies in chicken samples could then be calculated by reference to the positive control. This relationship is expressed as S/P ratio (Sample to Positive Ratio). For the test result to be valid the mean negative control absorbance should read below 0.3 and the difference between the mean negative control and the mean positive control should be greater than 0.15 . A software contained data (positive control, negative control, $s / p$ ratio and OD value) which were adjusted in such a way that when OD value of the samples that were obtained from ELISA reader are fed, the antibody titre of the samples obtained automatically. To get the antibody titer of all 92 samples in the particular plate, positive control and negative control should be kept fixed in the program only for that particular plate.

\section{Data analysis}

Data of antibody titer level of day-1, day-11 and day26 age of chicks of different farm were separately stored in Microsoft Excel 2007® spreadsheet program before it merged together and exported to analytical software to descriptive univariate analysis using STATA $11.2^{\circledR} 2011$ 
(Intercooled Stata 11.2, Stata Corp., College Station, texus, USA). Data of antibody titer level of two broiler strain were analyzed by using t-test through Graph Pad Prism 6.01v.

\section{RESULTS}

The maternal antibody titers obtained from broiler serum on day1 and day 11 are shown in Table 1 . The titer at $1^{\text {st }}$ day is greater than that at 11 th day in both strains. MDA level was protective and comparatively
Classic at 26th day (post vaccination) were found 131 and 7414 respectively. Table 3 showed significant variation $(\mathrm{P}<0.05)$ in average Maternally Derived Antibody (MDA) of strain Cobb-500 and Hubbard Classic at 1st, 11th and 26th day.

The average MDA level of the broiler strain Hubbard classic (flock-1) at $1^{\text {st }}$ day were lower than Cobb500. The average titer level of Cobb-500 (flock-2) was protective at the age of day-11 where as the Hubbard classic and Cobb-500 (flock-3) was not protective at age of day-11 and day-13 against

Table 1: MDA level of Cobb-500 and Hubbard Classic broiler strain at age of day-1 and day-11.

\begin{tabular}{|c|c|c|c|c|c|c|}
\hline \multirow{2}{*}{$\begin{array}{l}\text { Name of } \\
\text { Strain }\end{array}$} & \multirow{2}{*}{$\begin{array}{l}\text { Total } \\
\text { population }\end{array}$} & \multicolumn{2}{|l|}{ Day-1 } & \multicolumn{2}{|l|}{ Day-11 } & \multirow[t]{2}{*}{ Remarks } \\
\hline & & Sample size & Titer level & Sample size & Titer level & \\
\hline Cobb-500 & 600 & 20 & 9621 & 30 & 1963 & $\begin{array}{l}\text { Protective at } \\
\text { day-1 and day- } \\
11\end{array}$ \\
\hline $\begin{array}{l}\text { Hubbard } \\
\text { classic. }\end{array}$ & 550 & 20 & 4232 & 30 & 984 & $\begin{array}{l}\text { Protective at } \\
\text { day-1 but not } \\
\text { at day-11 }\end{array}$ \\
\hline
\end{tabular}

Table 2: Post vaccination titer level of two different strains at the age day-26.

\begin{tabular}{|c|c|c|c|c|c|}
\hline \multirow[t]{2}{*}{ Type of vaccine } & Broiler strain & Total population & Day-11 & Day-26 & Remarks \\
\hline & & & Titer & Titer & \multirow[b]{2}{*}{$\begin{array}{l}\text { Status: non- } \\
\text { protective. } \\
\text { Persistence of } \\
\text { MDA at day- } \\
11(>1000) \text {. }\end{array}$} \\
\hline $\begin{array}{l}\text { Intermediate, } \\
\text { Bursine-2 }\end{array}$ & Cobb-500 & 600 & 1963 & 131 & \\
\hline $\begin{array}{l}\text { Intermediate plus, } \\
\text { IBD Blen }\end{array}$ & Hubbard classic & 550 & 984 & 7414 & $\begin{array}{l}\text { Status: protective. } \\
\text { Non-persistence of } \\
\text { MDA at day- } \\
11(<1000) \text {. }\end{array}$ \\
\hline
\end{tabular}

Table 3: IBD antibody titer level at day-1, day-11, and day-26 of age groups.

\begin{tabular}{lllll}
\hline Age & Broiler strain & Mean \pm SEM & 95\% CI & p-value \\
\hline Day-1 & Cobb $(\mathrm{N}=20)$ & $9621.65 \pm 780.78$ & $7987.45-11255.85$ & 0.000 \\
& Hubb $(\mathrm{N}=20)$ & $4232.60 \pm 301.66$ & $3601.20-4863.99$ & \\
Day-11 & Cobb $(\mathrm{N}=30)$ & $1963.00 \pm 143.37$ & $1669.76-2256.23$ & 0.0001 \\
& Hubb $(\mathrm{N}=30)$ & $984.16 \pm 126.40$ & $725.63-1242.69$ & \\
Day-26 & Cobb $(\mathrm{N}=50)$ & $131.30 \pm 36.04$ & $58.86-203.73$ & 0.000 \\
\hline
\end{tabular}

higher in Cobb-500 broiler than Hubbard classic at $1^{\text {st }}$ day and $11^{\text {th }}$ day. MDA level in Hubbard classic at $11^{\text {th }}$ day (984) was not protective.

Both strain of broiler were vaccinated at $12^{\text {th }}$ day. The antibody titers of vaccinated (Oil Adjuvant) broiler on $26^{\text {th }}$ day are shown in Table 2. The antibody titer levels of Cobb-500 and Hubbard
IBDV. After vaccination at the age of day-12, the titer level was increased in case of Hubbard classic and titer level was declined in case of Cobb-500, due to vaccinated at $12^{\text {th }}$ day where the MDA titer remain high.

\section{DISCUSSION}




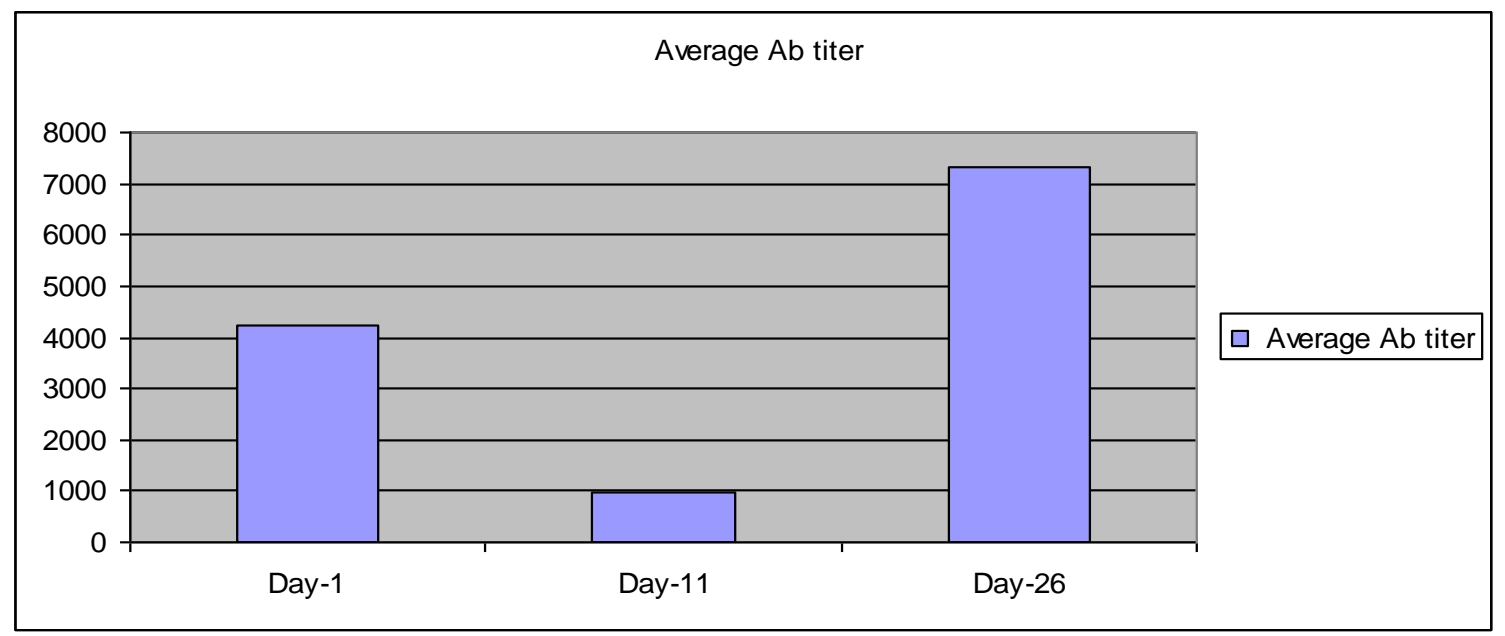

Figure 1. Mean titer level of Hubbard Classic (flock-1) at different age.

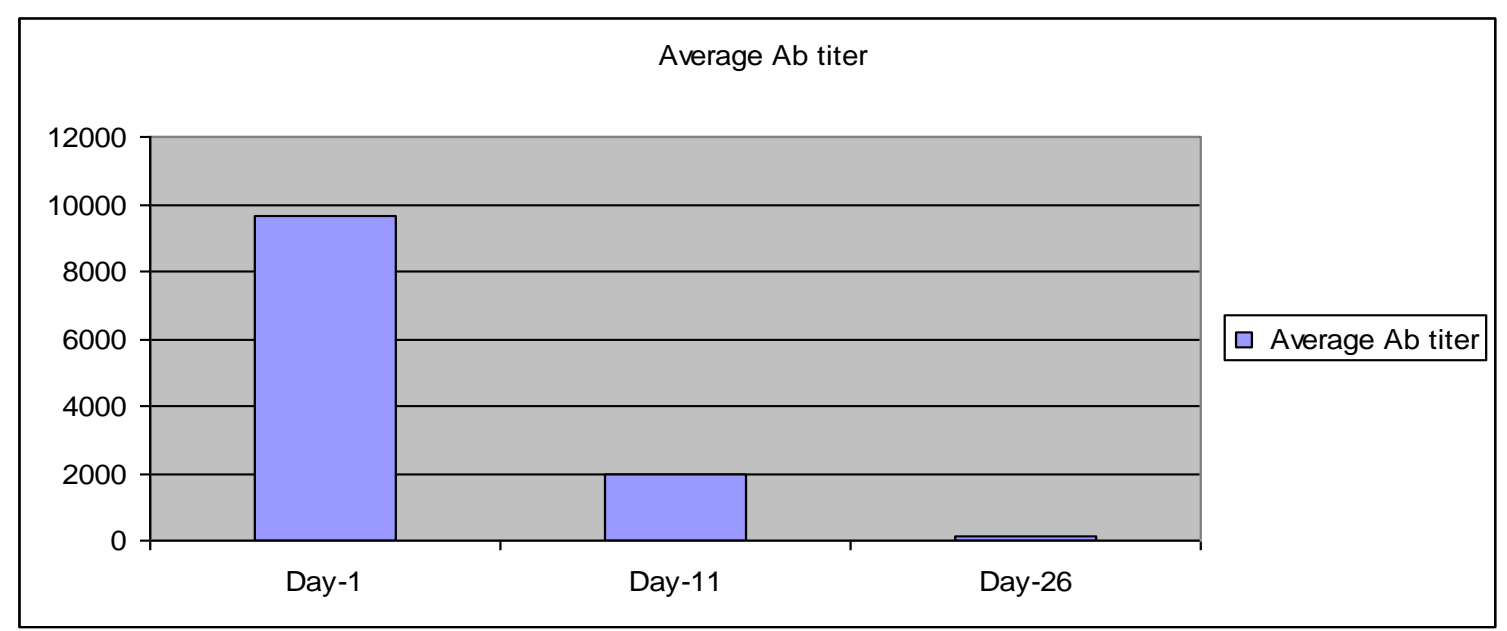

Figure 2: Mean titer level of Cobb-500, Flock-2 at different age.

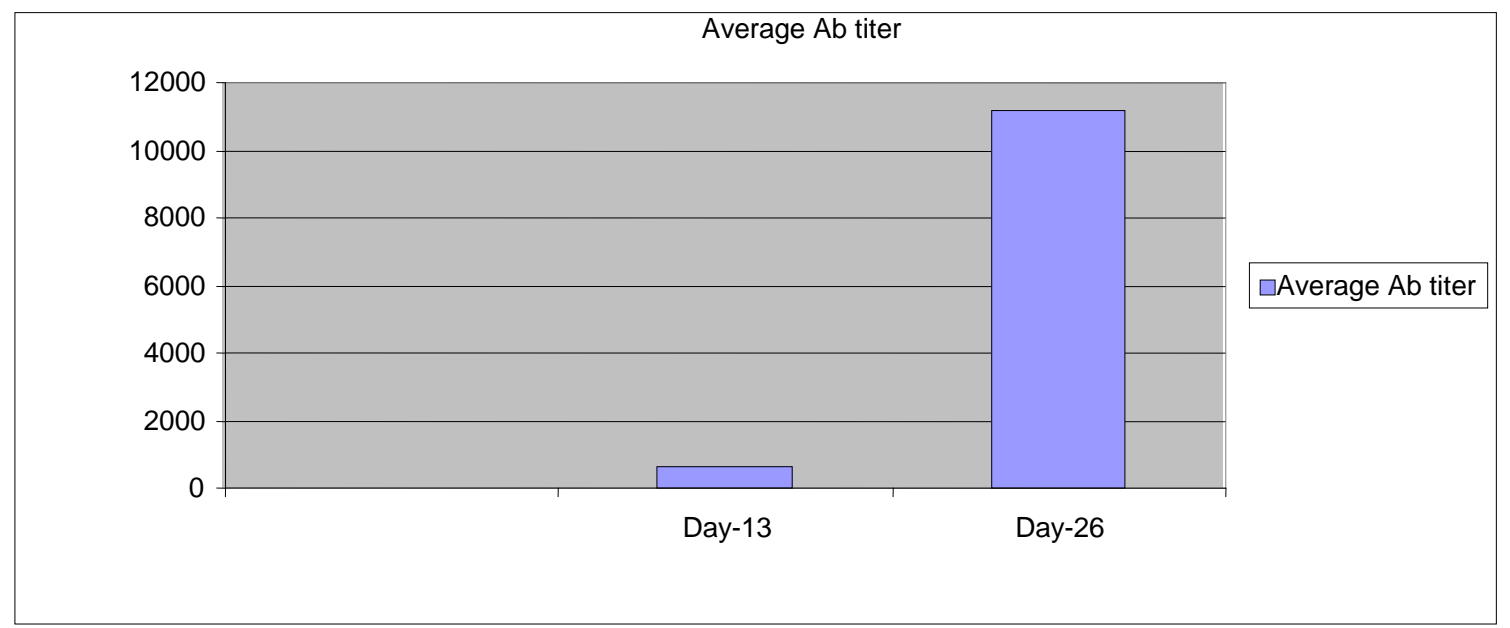

Figure 3. Mean titer level of Cobb-500, Flock-3 at different age.

The titer at $1^{\text {st }}$ day is greater than that at day 12 and this is in agreement with Phatak ${ }^{[19]}$, who stated that passively transferred antibodies from parent to chick usually wane after 7-14 days. Therefore, it is evident that the maternal antibodies of chicks are very protective on day 0 compared to day 12 . This titer was highly protective against IBDV. But when serum was collected serum on day-11 without any vaccination of anti-IBD vaccine, the ELISA titer were showed $1963.00 \pm 143.37$ and $984.16 \pm 126.40$ on Cobb-500 and Hubbard Classic, respectively. Fourteen days after vaccination (vaccination at day12) the titer of Hubbard Classic was raised to 7413.54 \pm 569.39 but titer level declined to $131.30 \pm 36.04$ for Cobb-500. This findings was in accordance with the findings of Shrestha et al ${ }^{[6]}$ who showed that the 
chicks should be vaccinated at around $14^{\text {th }}$ day got significant level of antibody titer at $29^{\text {th }}$ day of age. The MDA of Cobb-500 was higher than Hubbard classic. But there was significance difference in antibody titer level of those two strains of chicken at day-11 where the average titer level of Cobb-500 and Hubbard classic were 1963 and 984 respectively. At the age of day-11 the titer level of Cobb-500 was protective to IBDV whereas the titer level of Hubbard classic was not protective to IBDV. Alam et $a l^{[10]}$ indicates that maternally derived antibody level of Arbor Acres strain at day-1 of age was $6294.14 \pm 24.95$ which was higher than Cobb-500 and lower than that of Hubbard Classic strain. Shrestha et al ${ }^{[6]}$ showed that day old Broiler kasile contained high level of MDA was 5877.15, which was lower than Cobb-500 and higher than Hubbard Classic strain.

There was significant recession of titer level in Cobb-500 whereas the titer level of Hubbard classic was increased. Otherwise the history of sick bird and medication with antibodies was evident in case of Cobb-500 after vaccination. For the above reason vaccine may fail in case of Cobb-500. The average antibody titer level of strain Hubbard Classic and Cobb-500 at the age-26 were $7413.54 \pm 569.39$ and $131.30 \pm 36.04$. Here the chicks of Hubbard Classic exhibited higher titer level than the chicks of Cobb500. Cao et al ${ }^{[12]}$ presented immunological efficiency of IBDV by ELISA and found that MDA level was high at day-1. Malay et al ${ }^{[13]}$ found that MDA level was significantly lower at day-12 of age than day- 1 of age.

Jung et al ${ }^{[14]}$ mentioned that the half life of ELISA maternal antibody ranges from 4.2-12 days. According to Saijo and Higashihara ${ }^{[15]}$ the half life of MDA to IBD in chick was 3.46 days. Al-Natour et al [16] observed that medium level of maternal antibody protect the progeny up to 7-14 days of age. Maternal antibody lasted 14 days in local chicken ${ }^{[17]}$. According to Wisnsewsha and stisik ${ }^{[18]}$ MDA lasted until 11-19 days and sometimes 23 days after hatching. The half-life of maternal antibodies of IBD for broilers at $1^{\text {st }}$ day is 3.8 days ${ }^{[20]}$. So, the recommended vaccination time for Cobb-500 at the age of day-13 and Hubbard Classic at the age of day11 , respectively.

\section{CONCLUSION}

The study showed that there were variations in MDA between two broiler strains. The flock should be vaccinated before observing the persistence of MDA. The post vaccination titer would be non protective while the persistence of MDA remains high (>1000). The recommended vaccination time of the two broiler strain would be different: the time for Cobb500 at the age of day-13 and Hubbard Classic at the age of day-11, respectively.

\section{ACKNOWLEDGEMENTS}

The author greatly acknowledge to NATP and Department of Medicine and Surgery, CVASU, Bangladesh for financial and technical support.

\section{REFERENCES}

1. Jordan FTW, Pattison M (1996). Infectious Bursal disease. In- Poultry diseases. $5^{\text {th }}$ edition. pp: 205-215.

2. Toro H, Van Santen VL, Hoerr FJ, Breedlove C (2009). Effects of chicken anemia virus and infectious bursal disease virus in commercial chickens. Avi. Dis. 53: 94-102.

3. Jackwood DJ, Sommer-Wagner SE (2010). Detection and characterization of infectious bursal disease viruses in broilers at processing. Prev. Vet. Med. 97: 45-50.

4. Jackwood DJ, Saif YM (1987). Antigenic diversity of infectious bursal disease viruses. Avi. Dis. 3(1): 766-770.

5. Cosgrove AS (1962). An apparently new disease of chickens-avian nephrosis. Avi. Dis. 6: 385-389.

6. Shrestha P, Ahsan MM, Islam KMD, Billah MM, Mehedi M, Mitre S, Islam MR (2003). Seroprevalence of infectious bursal disease virus (IBDV) specific antibody in chicken. Pak. J. Biol. Sci. 6 (14): 1234 -1240.

7. Cho Y, Edgar SA (1972). Characterization of infectious bursal disease. Poult. Sci. 51: 6069.

8. Giambrone JJ (1987). Infectious bursal disease virus variants termed emerging problem. Poult. Digest. 46: 116-120.

9. Vandersluis W (1999). World Poultry Disease Update. World. Poult. 15: 30-33.

10. Alam J, Rahman MM, Sil BK, Khan MSR, Giasuddin, Sarkar MSK (2002). Effect of maternally derived antibody on vaccination against infectious bursal disease (Gumboro) with live vaccine in broiler. Int. J. Poult. Sci. 1(4): 98-101.

11. Bruce LH, Gary DB, Richard DM (1992). Subclinical infectious bursal disease in an integrated broiler production operation. J. Vet. Diagn. Invest. 4: 406 -411.

12. Cao-Yong C, Bi-Ying Z, Zhu J, Cao YC, Bi YZ, Zhu IM (1995). Application of Enzyme Linked Immunosorbent Assay for evaluation of immunological efficiency of chicks against IBD. Chinese. J. Vet. Med. 21: 9-10.

13. Malay M, Bhattacharyya HM, Duttagupta R, Pramanik AK, Sen GP, Mitra M (1998). Studies of maternally derived antibody level of different viral diseases in broilers. Indian. Vet. J. 75: 495-497.

14. Jung, Tsai-Hsiang, Lin-Dihfa, Sung HT (1995). Survey of maternal antibody status 
against IBDV and estimation of the vaccination point. J. Chinese. Soc. Vet. Sci. 21: 223-231.

15. Saijo K, Higashihara M (1998). Optimal time of initial administration of live vaccine for IBD in chicks with MDA. J. Japan. Vet. Med. Asso. 51: 647-651.

16. Al-Natour, Sil MQ, Ward LA, Saif YM, Stewart-Brown B, Keck LD (2004). Effect of different level of Maternally Derived Antibodies on protection against Infectious Bursal Disease Virus. Avi. Dis. 48(1): 177182.

17. Azab A, Hassan SM, Qubih TS (1999). Determination of maternal immunity against
IBD in beoiler chicks. Assiut. Vet. Med. J. 25: 211-215.

18. Wisniewska J, Stisik M (1999). Serum antibody titer after the first immunization of broilers against IBDV. Medy. Wateryn. 55: 48-51.

19. Phatak RK (2000). Vaccination failures and their solutions. N.500029 in Proc. Poultry Seminar, Hyderabad, India.

20. www.biochek.com 